\title{
O QUE AS GEOGRAFIAS DA GLOBALIZAÇÃO ENSINAM
}

\author{
What globalization geographies teach
}

\author{
Pedro Geiger \\ Instituto de Geografia - UERJ \\ pedro.geiger@gmail.com
}

\begin{abstract}
Resumo
Indaga-se quanto à natureza da globalização, dela ser um ciclo conjuntural estruturado no capitalismo, ou, a de ser uma transição para uma nova estrutura econômica e social. Aponta-se para as mudanças nas relações sociais de produção que acompanham os progressos da evolução tecnológica da base produtiva, destacando a ascensão da classe dos gestores do capital, os executivos, ou capitalistas assalariados e as sua relação com a Universidade. A geografia é apresentada como integrante das diversas instâncias, inclusive da base produtiva, e também expressa profundas transformações a exemplo da ascensão dos grandes emergentes na hierarquia dos Estados. $\mathrm{O}$ adensamento da movimentação de mercadorias no Pacífico Norte passou a superar a do Atlântico Norte. A escala geográfica ganha novos sentidos com a expansão da chamada economia virtual. Ao lado de economias nacionais de dimensão continental e subcontinental, desenvolveram-se cidades Estados, cidades ilha, como paraísos fiscais. Outro dilema presente se refere a opções entre crescimento e ambientalismo.
\end{abstract}

Palavras chave: globalização, acontecimento e necessidade, conjuntura e estrutura, capitalista assalariado, crescimento e ambientalismo, escalas geográficas da globalização.

\section{Abstract.}

The nature of globalization is questioned. Is it a conjuncture cycle in the capitalist structure, or is it more than this, a transition to a new kind of economic and social structure? One points to changes occurring in the social relations of production which accompanies the evolution of the technical progresses, as for instance, the ascension of the class of executives, or the wage capitalists and to their relations with the Universities. The geography is presented as a product related to all the instances, and also presents deep changes, as for example, the ascension of the large emergent States in the world hierarchy, or in the fact that the density of shipping in the Pacific North is now higher than in the Atlantic North. Geographic scale acquires new significance with the development of the virtual economy: beside the large national economies of a continental or sub-continental dimension, one sees city states, or city islands playing the role of fiscal paradises. The globalization geographies are also worsening some dilemmas, as to the options between growth and environment.

Key words: globalization, happening and necessity, conjuncture and structure, wage capitalists, growth and environment, geographical scales of globalization.

\section{Introdução: Qualificações geográficas.}

Geo UERJ - Ano 14, nº 23, v. 2, $2^{\circ}$ semestre de 2012 p. 509-523

ISSN: 1415-7543 E-ISSN: 1981-9021

http://www.e-publicacoes.uerj.br/index.php/geouerj 
As geografias que vêm cobrindo a superfície terrestre têm sido objetos de designações qualificativas. Elas podem ganhar nomes que se referem a qualificações dadas a extensões particulares de espaços ou de territórios geográficos. Por exemplo, a geografia das indústrias, ou, a geografia do Brasil. Ou então, podem receber nomes relacionados a como elas eram, ou são, durante determinado períodos históricos, como no título deste trabalho. Neste caso, as designações enunciam, implicitamente, a existência de interações entre as diversas instâncias ou práticas sociais que são particulares àquele período, assim como, à construção social de um espaço geográfico próprio para aquele período.

A qualificação de uma geografia segundo um dado período histórico pode estar fazendo referência a uma fase que se apresenta como uma dada conjuntura. Segundo a teoria marxista, a conjuntura é um momento de uma estrutura econômica social que é marcado pela presença de um dado nível de instâncias que atuam como um nível dominante. Por exemplo, na expressão a 'geografia dos descobrimentos', é feita a referência à conjuntura que resultou da invenção da caravela e que produziu as navegações dos séculos 15 e 16. Navegações que levara, à descoberta das América, à ampliação do comércio marítimo e a pé de cal do feudalismo e à afirmação do mercantilismo. Outro exemplo estaria na expressão a 'geografia da crise contemporânea` referente à conjuntura da crise econômica mundial iniciada no setor imobiliário americano em 2008, que mostraria os enlaces da crise imobiliária com os setores da economia e os caminhos da propagação da crise.

Numa outra opção, a qualificação temporal pode estar considerando não uma conjuntura, mas, uma estrutura econômica social fixada ao longo de determinado período histórico mais longo. O que envolve enfatizar na análise, o nível que é determinante desta estrutura econômica e social, ou seja, a sua base produtiva, (ALTHUSSER, 1979). Como no caso de se colocar para estudo a 'geografia do capitalismo`, por exemplo.

Cabe lembrar que o quadro mais geral que classifica os diverso níveis sociais, ou as práticas sociais, as distingue como econômicas, políticas, ideológicas e culturais. Todas estas práticas interagem entre si e cada uma delas com o todo, conduzindo a história. Porém o nível econômico é tido como determinante. Trazendo um exemplo para a compreensão da idéia: na Alemanha dos anos 30, a ideologia nazista se apresentava Geo UERJ - Ano 14, no. 24, v. 2, $2^{\circ}$ semestre de 2012 p. 509-523

ISSN: 1415-7543 E-ISSN: 1981-9021

http://www.e-publicacoes.uerj.br/index.php/geouerj 
como uma instância dominante no país, que foi capaz de empolgar a sua população e dar início à Segunda Grande Guerra. Contudo, é impossível desconsiderar a crise econômica alemã dos anos 20 como a base alimentadora das propagações de ideologias anti-sistêmicas, entre as quais a nazista acabou se impondo.

A conjuntura é um momento marcado pelo aparecimento de um acontecimento que passa a afetar uma dada estrutura (DELEUZE e GUATTARI, 1992). Que, eventualmente, pode interferir tão profundamente no andamento dos processos, a ponto de transformar totalmente a estrutura afetada. Foi o que aconteceu com a invenção da máquina, na passagem do mercantilismo ao capitalismo. Outro exemplo, mais radical, o acontecimento de uma erupção do Vesúvio acabou com a existência histórica de Pompéia. Outros exemplos, o assassinato do herdeiro do trono austro-húngaro, em Sarajevo, em 1914, um acontecimento de natureza social, foi o estopim para desencadear a Primeira Guerra Mundial. Hitler aconteceu, o nazismo aconteceu e ambos conseguiram conduzir o Mundo a uma guerra com 30 milhões de mortos.

Já a estrutura econômica social expressa um corpo construído, organizado, resultante de um processo envolvendo todas as instâncias, e que compreendem relações de necessidades de umas frente a outras. Não foi propriamente uma necessidade que fez o vulcão entrar em atividade, nem o disparo matar o sobrinho de Francisco José, ou alguém inventar o tear, e outro, a máquina a vapor. No entanto, instalado o processo e a estrutura capitalista, sua continuidade, ou a constituição de uma nova empresa capitalista, necessita de capital. Visto de outro modo, a continuidade do funcionamento do capitalismo exige a acumulação.

Os movimentos de um processo estrutural incluem, portanto, o atendimento a ditames de necessidades constituídas durante a organização da estrutura e durante o seu funcionamento. Necessidades, inclusive, se apresentam para a realização de ajustes, devidos à ocorrência de acontecimentos provenientes de dento ou de fora da estrutura em questão. A crise econômica mundial contemporânea é um acontecimento, ou uma conjuntura, ante a qual os dirigentes das grandes economias nacionais ou dos blocos de países procuram um ajuste que leve à retomada do crescimento.

Por outro lado, o aparecimento de novos acontecimentos e de novas conjunturas abre possibilidades para transformações mais profundas, mais estruturais. As geografias associadas ao aparecimento de novas conjunturas se apresentam, inicialmente, mais Geo UERJ - Ano $14, n^{\circ} .24$, v. 2, $2^{\circ}$ semestre de 2012 p. 509-523

ISSN: 1415-7543 E-ISSN: 1981-9021

http://www.e-publicacoes.uerj.br/index.php/geouerj 
como novas possibilidades, cuja realização se efetiva na medida em que as novas conjunturas acabam conduzindo ao estabelecimento de novos processos e de novas estruturas.

No que tange a processos e estruturas sociais, há a considerar outros aspectos. Um deles diz respeito aos graus de liberdade do homem e às suas limitações absolutas e relativas à cada época. $\mathrm{O}$ que lhe permite planejar em termos de possibilidades. Outro aspecto se refere à irreversibilidade (PRIGOGINE e STENGERS, 1991) e às complexidades crescentes da estrutura social. Ao contrário do movimento no espaço, onde o homem realiza marchas para frente e à ré, no movimento temporal, o sentido é sempre para frente. $\mathrm{O}$ tempo também compreende a acumulação social. $\mathrm{O}$ adensamento que vai preenchendo o espaço com uma população crescente e com ambientes socialmente produzidos. .

Ao longo do tempo, o homem, indivíduo, é o mesmo ser, que, enquanto vivo, concentra, em si, o seu passado, seu presente e seu futuro. Que acumula anos, experiências, memórias, mas, que também vê eles se desgastarem ao longo do tempo. A humanidade, a sociedade também vive a permanência do passado, do presente e o futuro em potencial. Ela acumula séculos de existência, de modo que ela é sempre, dialeticamente, a mesma e, ao mesmo tempo, uma outra. As permanências se apresentam com os entes mudando de função. O motor substituiu o cavalo no transporte, mas, o cavalo continua sendo criado, correndo em hipódromos, sendo utilizado nos jogos de pólo, puxando carruagens de passeio no Central Park de Nova York. O cão já não é utilizado para a caça de mamutes, para a subsistência, como a 30.000 anos atrás, hoje é trinado para encontrar sobreviventes em escombros de desabamentos.

Neste sentido, as velocidades dos movimentos físicos provocados pela prática social têm variado muito. Inclusive porque, diante de acumulações que provocam maiores complexidades, acelerações na capacitação de gerenciar o espaço social são requeridas, Desde a marcha a pé, mantida pela espécie, homo sapiens, às velocidades dos atuais balísticos, muito superiores á da rotação da Terra, que é de 1.667 kilometros por hora e às velocidades da luz, nas operações da Informática.

Ante todas estas considerações introdutórias, as perguntas que se fazem ao título deste trabalho são:

Geo UERJ - Ano 14, nº 24, v. 2, 2º semestre de 2012 p. 509-523

ISSN: 1415-7543 E-ISSN: 1981-9021

http://www.e-publicacoes.uerj.br/index.php/geouerj 
Qual a posição da prática geográfica, isto é, da construção social de geografias, na estrutura social dos níveis determinantes e dominantes?

A globalização é um conjunto de conjunturas concernentes ao capitalismo, ou se trata de uma transição para uma nova estrutura ou formação econômica e social?

Haverá limites para a acumulação social na superfície terrestre?

É o debate destes temas que o presente trabalho tratará a seguir.

\section{A prática geográfica como componente das demais instâncias.}

A rigor todas as instâncias compartilham o processo social, nenhuma é separada das outras. No entanto, cada uma possui momentos de alta autonomia. Pasteur manteve a sua religiosidade profunda, a separando da prática científica que o fez o descobridor da vida microbiana, enquanto outros perderam a fé ante o aparecimento do evolucionismo. Quanto à prática geográfica, ela possui particularidades próprias, dado o fato de lidar com espaço.

A existência de qualquer ente se encontra presente no ser, no homem, ao qual ela se apresenta na sua dimensão temporal e espacial (HEDEGGER, 1993). Por outro lado, a lembrança de um antigo encontro, ou de uma idéia antiga, é mais facilmente associada a um lugar no qual ocorreu do que a uma data precisa. Já foi sugerido, aliás, ser a geografia 'o local da memória' (PIVETEAU, 1995) Todas as instâncias, materiais e virtuais, se compõem de entes Deste modo, todas as instâncias ou práticas sociais possuem dimensões espaciais e temporais. Isto significa que a geografia é um campo formado pela composição de entes presentes na superfície terrestre.

A base econômica é um ente composto de entes, e a sua operação pelos agenciamentos sociais forma um nível de instâncias. Portanto, de acordo com as proposições expostas anteriormente, a base econômica e as operações econômicas da mesma, possuem dimensões espaciais e temporais.

As outras instâncias, as políticas, as ideológicas. a cultural, as sociais propriamente ditas, todas elas também se compõem de uma infinidade de entes e todas elas se realizam em dimensões espaciais e temporais. Resulta que as articulações entre as diversas instâncias, para comporem o mundo real, se realiza com integrações de suas dimensões espaciais e temporais, dando origem à geografia e à história. Processo que se

Geo UERJ - Ano 14, nº. 24, v. 2, $2^{\circ}$ semestre de 2012 p. 509-523

ISSN: 1415-7543 E-ISSN: 1981-9021

http://www.e-publicacoes.uerj.br/index.php/geouerj 
encontra nomeado na palavra formação, na expressão formação econômica e social (SERENI e LUPORINI, 1974).

A percepção da presença geográfica integrada na formação econômica social fez o Professor Milton Santos propor alterar a expressão clássica, lhe acrescentando o termo espacial. No entanto, tal medida é desnecessária, uma vez que o termo formação se compõe de forma e ação, como referências ao espaço ocupado pela forma e o tempo ocupado pela ação. Se a expressão e espacial pode ser dispensada da expressão marxista formação econômica e social, contudo, a teoria marxista deveria incluir, particularmente, a instância geográfica ao lado das mencionadas política, ideológica e cultural, Isto porque ela compreende as relações específicas da sociedade com a natureza.

Em artigo recente, considerei a base econômica, a instância dominante, como sendo constituída de um tripé, o qual, além de uma base técnica produtiva, e das relações sociais de produção, contaria ainda com um pé composto por um quadro geográfico específico (GEIGER, 2012). Exemplos históricos foram apresentados, como a constituição da Liga Hanseática, como sendo um suporte do desenvolvimento do mercantilismo, ou o da metropolização como suporte do capitalismo industrial.

Acontecimentos que ocorrem numa dada estrutura podem encontrar um terreno fértil que contribui para acelerar e expandir desenvolvimentos provocados pelo acontecimento. Por exemplo, acontecimentos políticos que conduziram à subida de Deng Xiaoping ao poder na China, encontraram um mercado de trabalho favorável em termos de custos, disciplina e aplicação, para o grande salto que seria dado pelo país, rumo a uma industrialização avançada. Por outro lado, porém, os arcabouços já implantados e imobilizados podem se tornar freios para a inovação. Durante a Segunda Grande Guerra, por exemplo, o esforço militar ampliou sobremaneira o parque industrial norte-americano. Posteriormente a expansão contemporânea da indústria do aço na China e no Brasil dotou estes países com maior competividade na produção de aço, uma vez que suas siderurgias, mais modernas, foram dotadas de inovações técnicas. As geografias estabelecidas podem atuar, portanto, quer oferecendo suporte a acelerações decorrentes de efeitos de acontecimentos, quer criando resistências à mudança.

Geo UERJ - Ano 14, nº 24, v. 2, $2^{\circ}$ semestre de 2012 p. 509-523

ISSN: 1415-7543 E-ISSN: 1981-9021

http://www.e-publicacoes.uerj.br/index.php/geouerj 
Via de regra, os acontecimentos possuem funções extremas. Podem destruir, como no caso do terremoto do Haiti, piorando uma situação que já era ruim. Ou podem acelerar o desenvolvimento, como ocorreu com o fim do tráfico de escravos no Brasil, em meados do século 19. Neste caso, se assistiu, por exemplo, a associação da expansão do regime salarial e da imigração italiana na então província de São Paulo, ponto de partida para tornar aquela região a mais desenvolvida do país. Tema clássico de Caio Prado Júnior. Já as estruturas, como arcabouços acabados oferecem resistências e tendem a reduzir as velocidades e as presenças de movimentos de mudança. Este passa a depender da capacidade se setores de sua população gerar, ou de absorver e potencializar novos acontecimentos com sinais positivos.

Como componente do arcabouço social estrutural, a geografia, inclusive através das condições físicas que oferece, influi nos movimentos que se desenrolam no interior das sociedades, em termos de suas direções, intensidades e velocidades. Acontecimentos do século 19, como a difusão mundial da bebida do café, paralela à urbanização, encontraram em São Paulo um quadro geográfico favorável para o desenvolvimento cafeeiro, inclusive pela presença de imenso território bastante aplainado. As condições sociais implantadas com esta geografia conduziram a que o núcleo urbano desta região se tornasse o principal centro do país da linha de desenvolvimento industrial associado ao capital privado, fazendo esta unidade da Federação passar a ser chamada, durante décadas, de a locomotiva do país. O acontecimento da localização de Brasília é um exemplo clássico de criação de um novo quadro geográfico, dotado de potencial espacial capaz de influir nos processos sociais do país. Novos desenvolvimentos regionais, no Centro Oeste e no Norte foram diretamente associados ao desenvolvimento de um Distrito Federal. Embora não se possa pensar em relações mecânicas no mundo social, isto não significa a ausência total de influências como aquelas descritas pelo modelo gravitacional aplicado a sistemas urbanos.

Por outro lado, quadros geográficos intra-urbanos construídos no passado, segundo padrões urbanísticos anteriores à introdução da circulação automóvel, têm se apresentado frequentemente como obstáculos a renovações imobiliárias. As renovações, em economias de propriedades provadas dependem das decisões dos proprietários de imóveis e a intervenção do poder público através de desapropriações pode ser demasiado custosa. Outras motivações associadas às formas espaciais também Geo UERJ - Ano 14, nº 24 , v. 2, $2^{\circ}$ semestre de 2012 p. 509-523

ISSN: 1415-7543 E-ISSN: 1981-9021

http://www.e-publicacoes.uerj.br/index.php/geouerj 
comparecem influindo nos movimentos da estrutura intra-urbana. Por exemplo, o desejo dos moradores de dispor de espaços livres em torno de suas habitações. É a conjugação de todas estas condições que, caso a caso, darão margem a tendências optantes, entre gentrificação, ou de construção de novos centros urbanos. O caso da mudança da capital de Goiás, de Goiás para a planejada Goiânia, nos anos 40, já na era do automóvel (repetindo Minas Gerais, que transferiu sua capital, de Ouro Preto para Belo Horizonte, em 1890), é um exemplo da necessidade sentida de mudar a capital, cidade fadada a crescer, por razões geográficas. Já no Rio de Janeiro, alternaram-se estratégias de gentrificação e de criação de novos bairros. Como nos casos da expansão da Barra da Tijuca e nas renovações na Lapa e na Zona portuária.

Nos exemplos acima apresentados são sempre observados os encontros entre acontecimentos e estruturas. No que tange à estrutura presente, como já foi dito, ela exerce sempre um papel de resistência à mudança, o que, em parte, se relaciona historicamente com o estabelecimento da propriedade privada. De certo modo, todas estas questões, que envolvem o jogo de acasos e causalidades, ou, acontecimentos, processos e estruturas, e o papel da propriedade privada nos processos sociais, já se encontram projetadas na Ideologia Alemã de Marx e Engels (1996). Quanto à geografia, não se tratando propriamente um acontecimento, ela sendo, antes, um componente de uma estrutura, passou a ser considerada, até recentemente, como uma prática e um objeto comprometido com o conservadorismo. Que fez Yves Lacoste dizer que ela foi feita para a guerra.

\section{A Globalização é uma conjuntura ou uma nova estrutura?}

Enquanto escrevo este artigo, setembro de 2012 ultima-se os preparativos para uma conferência do Centro Humboldt, na Argentina, a se realizar em outubro deste ano, sob o título de A Hora da Desglobalização. Aparentemente, o que os organizadores querem dizer é que a globalização é uma conjuntura avançada do capitalismo e que dar fim a ela serviria a dar fim ao capitalismo. Ou será o contrário? Dar fím a ela seria manter o capitalismo? A globalização seria uma conjuntura que se transforma em uma nova estrutura e cujo fim atenderia apenas ao retorno de formas anteriores do capitalismo, ou mesmo, a estruturas pré-capitalistas que se encontram embutidos nas formações econômicas sociais do mundo? Naturalmente, cabe a cada leitor ter a sua Geo UERJ - Ano 14, no . 24, v. 2, $2^{\circ}$ semestre de 2012 p. 509-523

ISSN: 1415-7543 E-ISSN: 1981-9021

http://www.e-publicacoes.uerj.br/index.php/geouerj 
opinião e ao futuro fornecer a resposta do real. O possível é expor fatos para uma argumentação.

Antes, lembre-se que falar em desglobalização implica em se alinhar com aqueles que restringem a aplicação do termo globalização para os tempos contemporâneos e contra a corrente de historiadores que alega ter sempre havido globalização, no sentido da difusão da espécie humana pelo planeta e do estabelecimento de conexões entre os lugares. Outra corrente chamada de 'quinhentista' considerando o desconhecimento da América nos 'velhos continente', admite a globalização apenas a partir do século 16. Eu tenho me alinhado em considerar a globalização como um fenômeno contemporâneo levando em conta ter sido cunhada na contemporaneidade, a sua difusão pela mídia e a sua internalização na população comum.

Em termos de metáfora é dito que, com a globalização, o planeta se encolhe. Não só o planeta, também o espaço interplanetário se encolhe, , considerando os veículos já colocados no planeta Marte. Velocidades crescentes são procuradas no transporte, como no caso da utilização do motor a jato e da balística; na comunicação, através da informática, um dos marcos técnicos da globalização; e na indústria, igualmente pela utilização da informática e da robotização. Através da informática a transmissão à distância e ao vivo inclui imagens, de paisagens, de eventos ao vivo, que faz a linguagem da imagem ganhar novas forças políticas.

A aceleração dos movimentos acompanha a história do homem. A maratona de Leônidas, na antiga Grécia, nos fala da velocidade como necessidade. Na atualidade, planos de saúde incluem transporte aéreo a segurados, quando necessários, em casos de remoção urgente a hospitais distantes.

A velocidade atende a necessidades criadas. Ao longo de toda a história ela foi tecnicamente incrementada inclusive para deliberar e administrar sobre um mundo crescentemente complexo. Sendo que a globalização só se tornou possível depois da invenção do computador e das suas velocidades. O processo capitalista vive uma contínua expansão vertical e horizontal, fundada na acumulação, necessária para ele se manter vivo, e a sua expansão vertical é tanto mais dinâmica, quanto maior for a velocidade da circulação dinheiro/capital. A sua expansão horizontal cobre extensões crescentes de território, que devem ser conectados entre si. A história do capitalismo se realizou no contexto político de Estados/Nações, sendo que coube aos Estados atuar Geo UERJ - Ano 14, no . 24, v. 2, $2^{\circ}$ semestre de 2012 p. 509-523

ISSN: 1415-7543 E-ISSN: 1981-9021

http://www.e-publicacoes.uerj.br/index.php/geouerj 
para garantir que seus territórios fossem providos de sistemas de transporte e comunicação operando a velocidades crescentes.

A velocidade também é requerida no plano da gestão, de governos e empresas, na tomada de decisões. Estas, no entanto, são frequentemente retardadas pelas razões inerciais presentes nas estruturas estabelecidas, como mencionado anteriormente. A globalização mostra um comportamento mais convergente dos Estados/Nações, atuando coletivamente, no trato da base econômica produtiva, encarada como sistema mundial, particularmente, nas suas instâncias comercial e financeira. O trato político tem sido mais divergente. Contudo, credita-se a esta cooperação internacional no plano econômico, parte do clima de paz mundial entre as grandes potências. Diferente do cenário dos anos 30, quando a crise econômica mundial, com semelhanças à crise atual, viu países se voltarem a soluções particulares, como Roosevelt estabelecendo a seguridade social, a social security, nos USA e Hitler rearmando e levando a Alemanha à guerra. A crise dos anos 20/30 colocou a ideologia como nível dominante, enquanto no presente o nível econômico é simultaneamente, um nível determinante e dominante para grande parte da população. O poder dissuasivo da bomba atômica e a dificuldade crescente de mobilizar cidadãos para guerras de conquista, são outras fontes de sustentação da paz mundial.

O alargamento do horizonte de pesquisas e tecnologias que ocorre na contemporaneidade, em diversas áreas, como na genética, ou na nanotecnologia, se articula com futuras aplicações em práticas sócias correntes. No entanto, a base técnica econômica atual está sendo mobilizada para novas práticas com objetivos virgens, que não atendem a interesses de atendimento individualizado, mas da sociedade como um todo. Como é o caso da criação de estação espacial internacional, ou da construção do super-acelerador de partículas na Suíça.

A injeção da ciência e da tecnologia se realiza em todas as instâncias sociais, incluídas nas da gestão de negócios, nas de governo, e nas da política. Não se concebe mais um capitalista, ou um governante, sem maior formação acadêmica, á frente de uma corporação transnacional, ou de uma esfera executiva de Estado, a não ser que tenha ao lado um assistente a quem deve delegar algum poder. A globalização se caracteriza pela ascensão generalizada dos executivos, dos gestores do capital, ou dos capitalistas assalariados, par utilizar uma categoria criada por Michal Kalecki (1976). Em Geo UERJ - Ano 14, nº. 24, v. 2, 2º semestre de 2012 p. 509-523

ISSN: 1415-7543 E-ISSN: 1981-9021

http://www.e-publicacoes.uerj.br/index.php/geouerj 
substituição a políticos ou homens de negócio tradicionais, na direção de Estadas, de empresas, de instituições internacionais. Ampliam-se as pontes entre estas organizações e a Universidade, um aspecto que serve àqueles que vêm semelhanças entre os tempos atuais e a Idade Média. Dilma Ioussef e Barak Obama não são políticos tradicionais, mas, exemplos desse movimento de uma nova classe em ascensão ao poder. O que parece contribuir para o prestígio deles. A realização do ideal de Platão em andamento?

Aliás, na sucessão de modos de produção não se observou classe dominada subir ao poder, mas uma terceira situada fora da contradição direta dominador/dominado. Nem escravos, nem camponeses assumiram a liderança de sociedades depois da derrubada dos modos de produção escravagista e feudal $\mathrm{Na}$ passagem do feudalismo para o capitalismo, ascendeu uma classe burguesa que se foi constituindo nas cidades, centros comerciais, reunindo comerciantes, fazendeiros e outros que se iam tornando empresários industriais (WOOD, 2001). Aparentemente, a ascensão dos executivos, ou dos ayatolás, nos países de fundamentalismo islâmico, não seria mais um indício do movimento do fim do capitalismo, pelo menos como o conhecíamos (GRAHAM e GIBSON, 2006)? Valeriam lembrar também a ascensão de novas formas de organização no interior das sociedades civis adiantadas, como as ONGs.

No setor do trabalho comum também são observadas mudanças, como a substituição da antiga divisão fordista de trabalhadores, entre 'colarinhos brancos e 'colarinhos azuis` por trabalhadores qualificados e não qualificados (SCOTT. 2007).

No plano geográfico, são inúmeras as alterações do mapa econômico político. Cita-se a emergência do BRICS e a formação de uma nova hierarquia política dos Estados. Após a Segunda Grande Guerra, viu-se a instalação de um mundo bi-polarizado pelos Estados Unidos e pela antiga União Soviética. Ao que se seguiu uma fase unipolar, a partir de 1991, com o desmanche da União Soviética, e que agora evolui para um formato multipolar. Outros aspectos dizem respeito à difusão de uma intensa urbanização por todas as partes do mundo; à multiplicação de formação de blocos regionais econômicos e políticos de países; ao adensamento da navegação no Oceano Pacífico Norte, superando a do Atlântico Norte, dada a presença da China, Japão e dos 'tigres asiáticos`. . Edição do THE ECONOMIST de 4 de abril de 2002, mostrava movimento de 2,1 bilhões de toneladas das margens a leste do Atlântico Norte, para o oeste, e de 1,6 bi no sentido oposto. No Pacífico Norte, ao contrário, o movimento Geo UERJ - Ano 14, nº 24, v. 2, 2º semestre de 2012 p. 509-523

ISSN: 1415-7543 E-ISSN: 1981-9021

http://www.e-publicacoes.uerj.br/index.php/geouerj 
alcançou 7,3 bi, de do oeste para leste, e 3,7 de leste para oeste. O movimento oeste/leste inclui as exportações chinesas para os Estados Unidos.

A escala ganha novos significados na época da globalização. No começo do capitalismo, na era da ferrovia à carvão, Alemanha, França, Grã Bretanha, eram considerados grandes países em extensão territorial. Rússia, Brasil, China eram demasiado extensos para serem bem integrados, quando a sua industrialização se encontrava ainda em seus primeiros estágios. A extensão demasiada as enfraquecia. Os Estados Unidos foram os primeiros a instituir um capitalismo industrial nacional desenvolvido em escala continental, e foram seguidos pela tentativa da antiga União Soviética. A Europa de Hitler, a ser comandada pela Alemanha, compreendia a idéia de um poder em escala continental, ponte para conquistar o mundo todo. $\mathrm{O}$ andamento do processo capitalista industrial após a Segunda Grande Guerra foi valorizando os países de dimensão continental e subcontinental, e que se expressou na emergência do BRIC. Inclusive, superou os limites dos países independentes para alcançar esta escala, como na formação da União Européia.

No caso da União Européia se chegou a instituir moeda única, o Euro, e Banco Central único. No entanto, a manutenção de autonomias nacionais, como nas áreas fiscais e orçamentárias, associadas aos desequilíbrios nos balanços comerciais entre os países membros tem agravado a crise na Europa.

O avanço da globalização manifestou a maior separação entre o capitalismo industrial, agora também chamado de economia real, e o capitalismo financeiro com suas faces de economia virtual. O capitalismo financeiro, de economia virtual não necessita de base territorial para a sua expansão, pode operar bilhões e trilhões de divisas a partir de uma cidade Estado como Cingapura, ou de pequena cidade ilha como Cayman. Paraísos fiscais é a designação ganha por estes lugares, na medida em que fortunas de outros países são para lá deslocados, para escapar da fiscalização dos governos de sua origem, como anteriormente este papel se concentrava em bancos suíços. Uma das reivindicações dos correntes movimentos sociais anti-sistêmicos é a da imposição de novos regulamentos aos chamados paraísos fiscais. Portanto, a geografia da globalização mostra a simultaneidade do papel de entidades de escalas geográficas dispares na economia da globalização. Estes papéis exercidos pelas entidades

Geo UERJ - Ano 14, nº 24, v. 2, 2º semestre de 2012 p. 509-523

ISSN: 1415-7543 E-ISSN: 1981-9021

http://www.e-publicacoes.uerj.br/index.php/geouerj 
geográficas realizam também a reassunção da Geografia na ciência social, expressão cunhada por Edward Soja ( 1993).

A contemporaneidade exibe também a amplificação das preocupações com a questão ambiental. Um tema que se articula com a questão da qualidade acumulativa que o capital tem. Esta questão da inexorabilidade da acumulação mantida pelo capital é tratada, entre outros, por István Mészáros (2011) e por David Harvey (2012). Para Mészáros, a rigor, os problemas postos à sociedade humana não se encontram propriamente, no capitalismo, mas no capital. Estes são assuntos que encerram este trabalho, em sua conclusão.

\section{Conclusão.}

O capital subsiste enquanto consegue manter a sua natureza acumuladora, a de investir para criar mais dinheiro da qual parte volta a investir, na forma de capital. Mesmo nos Estados com maior socialização dos meios de produção, o crescimento se fundamenta na acumulação provida por capital. O capital está fadado à permanência na vida social, atravessando diferentes modos de produção, como é o caso da feira, ou do mercado?

Neste trabalho não se trata da questão das formas de apropriação do excedente produzidos pelo capital, apenas do problema da acumulação crescente, que é da natureza do capital.

O discurso ambientalista incorpora, cada vez mais, o discurso contra o crescimento e contra o capital, destacando os problemas ambientais que ele cria. De certo modo estão se repetindo as ideologias e os discursos anti-consumistas vigentes nos anos 60/70. Deste modo, o atual discurso anticapitalista e contra o neoliberalismo criador da globalização passou a ser, simultaneamente, um discurso crítico por razões de luta de classe e por razões de defesa do meio ambiente, ante a aceleração de sua exploração.. Este neoliberalismo expressaria liberdades maiores permitidas pelos governos dos Estados capitalistas aos gestores do capital, desde os anos 70, que deram margem a um novo ciclo de crescimento, à globalização e ampliando, entre outros problemas, os do meio ambiente.

A grave crise econômica contemporânea tem levado por si mesma, a um retorno à presença maior do Estado em diversas instâncias, como no socorro a empresas privadas sem caixa e no controle das práticas de negócios. Numa perspectiva histórica, teria

Geo UERJ - Ano 14, n⿳⺈.24, v. 2, $2^{\circ}$ semestre de 2012 p. 509-523

ISSN: 1415-7543 E-ISSN: 1981-9021

http://www.e-publicacoes.uerj.br/index.php/geouerj 
havido no após Segunda Grande Guerra, a instalação de um ciclo de forte participação do Estado para a reconstrução da economia capitalista, caso do Plano Marshall, e de instituição, particularmente na Europa, do chamado Estado previdenciário, como defesa da difusão do comunismo. Esgotado este ciclo, seguiu-se o chamado neoliberalismo fundado em gigantesca expansão da economia virtual financeira e na aplicação de capitais na industrialização crescente dos chamados emergentes. Novamente, a crise se agravou, com a evaporação de dezenas de trilhões de dólares da economia virtual, nos seus jogos com derivativos. Agora, aparentemente, se retorna para uma nova presença maior dos Estados na economia. Só que, este retorno tem o endereço de um retorno ao crescimento. Neste ponto é que se mantém um dos dilemas com o capital, a opção entre crescimento e meio ambiente equilibrado.

Como mencionado, a atuação dos Estados na economia se realiza atualmente de forma bastante coordenada, tendo nos extremos a China, governada por partido comunista e os Estados Unidos, modelo de domínio de economia de mercado. Uma instituição relativamente formal foi estabelecia para a gestão comum da economia mundial, o G20. O objetivo do Brasil dos USA, da China, do G20 é o crescimento. Mesmo porque parar o crescimento significaria manter as atuais desigualdades que incluem a distribuição do poder, o que certamente, poucos países aceitariam. Como fica então o dilema crescimento/meio ambiente?

Filosoficamente poder-se-ia especular, em defesa do crescimento que a solução estaria na expansão do homem pelo Universo, que este o sentido da aventura extra terrestre. Não se trata propriamente de procurar vida, civilizações, em outros planetas, mas, de encontrar condições para implantar as nossas.

\section{Referências:}

ALTHUSSER, Louis, Materialismo histórico, e materialismo dialético, AlthusserBardiou org., Materialismo Histórico e Materialismo Dialético, Teoria, Coleção base, 19, São Paulo, Global Editora, 1979.

DELlEUZE, Gilles e GUATTARI, Felix, O que é a Filosofia, São Paulo, editora 34, 1992.

GEIGER, Pedro P., Tópicos da Economia Política da Globalização, Susana M.M. Pacheco e Mônica Sampaio Machado, organizadoras, Globalização, políticas públicas Geo UERJ - Ano 14, nº 24, v. 2, $2^{\circ}$ semestre de 2012 p. 509-523

ISSN: 1415-7543 E-ISSN: 1981-9021

http://www.e-publicacoes.uerj.br/index.php/geouerj 
e reestruturação territorial: 203-221, Rio de Janeiro, Viveiros de Castro Editora Ltda., 2012.

GRAHAM, Julie e GIBSON, Katherine, THE END OF CAPITALISM (as we know it), Minneapolis, Minnesota University Press, 2005

HARVEY, David, O Enigma do Capital e as Crises do Capitalismo, São Paulo, Boitempo, 2012

HEIDEGGER, Martin, Ser e Tempo, 1ª edição, Petrópolis, Vozes, 1993.

KALECKI, Michal, Teoria de Dinâmica Econômica, Os Pensadores, Volume XLVII, São Paulo, Abril S.A. Cultural e Industrial, 1976.

MARX, Karl e ENGELS, Freseric, A Ideologia Alemã (Feuerbach), 10 a edição, São Paulo, HUCITEC, 1996.

MÉSZÃRIS. István, Estrutura Social e Formação de Consciência, Volume II: A dialética da estrutura e da história, São Paulo, Boitempo, 2011.

PIVETEAU, Jean-Luc, La Geographie est-elle lê lieu de la memoire? L'Espace Geographique, 24 (2) : 113-123.

PRIGOGINE, Ilya e STENGERS, Isabelle, A Nova Aliança, Brasília, UnB, 1991.

SCOTT, Allen J., Capitalism and Urbanization in a New Key? The Cognitive-Cultural Dimension, Social Forces, volume 85, number 4: 1466-1482, The University of North Carolina Press, June 2007.

SERENI, E. e LUPORINI, C.,. El concepto de formación econômica social, Buenos Aires, Siglo XXI, 1974.

SOJA, Edward, Geografias Pós-modernas: a reassunção do espaço na teoria social e crítica, Rio de Janeiro, Jorge Zahar Editor, 1993.

WOOD. Ellen, M., A Origem do Capitalismo, Rio de Janeiro, Editora Zahar, 2000.

Artigo encaminhado para publicação em setembro de 2012.

Artigo aceito para publicação em novembro de 2012.

Geo UERJ - Ano 14, nº 24, v. 2, $2^{\circ}$ semestre de 2012 p. $509-523$

ISSN: 1415-7543 E-ISSN: 1981-9021

http://www.e-publicacoes.uerj.br/index.php/geouerj 